\title{
On the Theoretical Construction of the Structural System of Semiotic Atoms in the Semantic Signs of Poetic Narrative Texts
}

\author{
Jun $\operatorname{Luo}^{1} \&$ Qing Yin ${ }^{1}$ \\ ${ }^{1}$ School of Foreign Languages, Zhaotong University, China \\ Correspondence: Jun Luo, School of Foreign Languages, Zhaotong University, Yunnan, China. Tel: \\ 86-15087773105. E-mail: 531678237@qq.com
}

Received: January 13, 2016

Accepted: January 17, $2016 \quad$ Online Published: February 26, 2016

doi:10.20849/ajsss.v1i1.16

URL: http://dx.doi.org/10.20849/ajsss.v1i1.16

\begin{abstract}
The studies of poetic narratology has been extended to the macro-studies of the narrative language of poetic narrative texts ranging from narrative grammar to narrative model with a special attention paid to the exploration of the semiotic atoms of its semantic narration and the semiotic atoms of its pragmatic narration in poetic narrative texts as well as their interrelationships. What hasn't been paid attention to in this area is the atomic structural system of the semiotic atoms of the narrative signs in poetic narrative texts. Grounded on the absence of studies in this regard, this essay aims to deal with the theoretical construction of the structure of the semiotic atoms of the semantic signs in the narrative language in the narrative poetic texts in terms of the semiotic atoms of the phonetic narration, the semiotic atoms of its semantic narration, the semiotic atoms of its pragmatic narration, the semiotic atoms of its grammatical narration as much as the semiotic atoms of its spatial narration in poetic narrative texts to develop and improve the theories of poetic narratology and expand its studies from macro-studies to micro-studies.
\end{abstract}

Keywords: poetic narrative texts, poetic narratology, theoretical construction

\section{The Narrative Semiotic Atoms in Narrative Texts}

Based on the light thrown by the basic theories of structural linguistics, the narrative language has been treated as a sub-system of the whole language systems in narrative studies. This sub-system has been termed as the system of narrative language and sign in narrative texts. In a similar way, the narrative language and sign in poetic narrative texts ought to be considered as another sub-system of the whole language system and be termed as the semiotic systems of poetic language and signs in poetic narrative texts. It has been possible that the strong influence of post-classic narratology on narrative studies and the authority it has enjoyed in this academic area has focalized the previous studies in narrative theories on the macro-studies of the narrative language and sign in narrative texts and the present studies of narrative theories shift gradually from the previous formalized studies of narrative texts to their present contextualized studies. What can be seen in that shift is that the influences of post-classic narratology has been so strong that many scholars has been devoting much of their time to it in a macro way and at the same time neglecting the micro-studies of narrative theories directed at the atomic structure of narrative language and sign in narrative texts. Therefore, the atomic structural system of the narrative language and sign in poetic narrative system needs to be explored and noticed in the academic area of narrative studies as well as poetic studies. Among the structural system of narrative texts, the semantic atom together with the pragmatic atom of poetic narrative texts is likely to be both the smallest linguistic and semiotic unit of the semantic and pragmatic system of semiotic signs in narrative texts. Those atoms might send, transmit and receive the crucial information of the poetic narrator's narrative action in poetic narrative texts by the virtue of a series of different operating maxim of narrative actions by transforming its own structures to play either a progressive or a preventive role in the process of constructing the structural system of narrative language in poetic narrative texts so as to send, transmit and receive the poetic narrator's narrating information while regarded as micro-vehicle of semiotic and pragmatic signs.

\section{The Narrative Semiotic Atoms in Poetic Narrative Texts}

The atoms of the semiotic signs in poetic narrative texts mentioned afore are the structuralized representation or characterization of the narrative semiotic models in poetic narrative texts because they have on the one hand described, categorized and generalized the narrative action models of the narrative semiotic signs of poetic 
narrative texts in a relatively complete fashion and on the other hand they have improved the structural system of the semiotic atoms of poetic narrative texts. Nonetheless, they have also carried a certain kind of potential dangers: they might replace the explicitness or universality properties of the atomic structure of the entire semiotic signs of poetic narrative texts with its implicitness or particularity. Hence, poetic narrative text, as one type of the narrative texts needs a special distinction of the structural model, structural property, generative mechanism and combination rules of the atomic structure of its semiotic structure from those properties of the poetic narrative text itself to prevent the atomic structure of the semantic signs of poetic narrative texts from being buried in the studies and explorations of some other types of narrative texts. In the light of the macro-structure of the narrative language of poetic narrative texts, the narrative language of those texts is also a semiotic sub-system of narrative language whose semiotic atoms in that narrative text has a relatively stable, regular and orderly internal atomic structure that can categorize those atoms into the following five sub-types of semiotic atoms through a certain rule of arrangement, distribution and combination: the semiotic atoms of the phonetic narration, the semiotic atoms of its semantic narration, the semiotic atoms of its pragmatic narration, the semiotic atoms of its grammatical narration as much as the semiotic atoms of its spatial narration in poetic narrative texts.

\section{The Structure of the Semiotic Atoms in Poetic Narrative Texts}

The structure of the semiotic atom in poetic narrative texts is a theorized and systematized exploration of the structure of its semiotic atom that contains primarily the semiotic atoms of the phonetic narration, the semiotic atoms of its semantic narration, the semiotic atoms of its pragmatic narration, the semiotic atoms of its grammatical narration as much as the semiotic atoms of its spatial narration in poetic narrative texts under both the foregrounding and backgrounding of phonetics, phonology, semantics, pragmatics, grammatics and narratology for the aim of making a basic exploration of their structural properties, which is an academic categorization and summarization of the phonetic structure, phonological structure, the semantic structure, the pragmatic structure, the grammatical structure and spatial structure of the semiotic atoms corresponding to the theories mentioned above respectively based on the aim of expanding and broadening the structural studies of the structure of the semiotic atoms of poetic narrative texts on the basis of examining the generative mechanism and structural regulation in the generation of the structure of the semantic atoms in poetic narrative texts within the development of poetic narratology. It is certain that the study of the structure of the semiotic atoms in poetic narrative texts is likely to sharpen some scholars' understanding of the certainty of the structure of the semiotic atoms in poetic narrative texts by helping them get away from the confusion and blindness of its uncertainty for the purpose of going to its certainty in a gradual way.

\section{The Structural System of Semiotic Atoms in Poetic Narrative Texts}

The structural system of semiotic atoms in poetic narrative texts is the system directed at the generation system and operation mechanism of some basic theoretical framework based on a series of narrative actions, narrative discourses, narrative grammars and narrative contexts in poetic narrative texts with an emphasis on the structural foundation of the linguistic certainty instead of uncertainty of the semiotic atoms in the poetic narrative texts. In fact, it is this very certainty of the semiotic atoms in the poetic narrative texts that is possible to disambiguate the semiotic ambiguity and pragmatic ambiguity produced in the process of the submission, transmission and acquisition of the narrative information between the semiotic structure and the semantic structure in poetic narrative texts. Therefore, it will be proposed in this essay that the semiotic sign of narrative poetry is an organic, a complicated and multi-layered structural system consisting with various semiotic atoms in poetic narrative texts that have been ordered, distributed and organized in accordance with certain structural law in different ways. Also, that atomic system in poetic narrative texts has its own laws in the light of structural distribution and operation mechanism in poetic narrative contexts. Nevertheless, for the sake of the typicality and canonicality of the semiotic atoms in poetic narrative texts, the successive argumentation of this essay will elaborate the existence of and make an initial study of the semiotic atoms in poetic narrative texts in the following four folds rather than dig out all the semiotic atom at one setting impossibly: the semiotic atoms of the phonetic narration in poetic narrative texts, the semiotic atoms of the semantic narration in poetic narrative texts, the semiotic atoms of the pragmatic narration in poetic narrative texts, the semiotic atoms of the grammatical narration in poetic narrative texts as much as the semiotic atoms of the spatial narration in poetic narrative texts.

First of all, the semiotic atoms of the phonetic narration in poetic narrative texts are grounded on the basic unit of narration that has been closely related to the phonetic components in a micro sense. Out of question, those atoms have much to do with the structural musicality of poetic narrative texts because they can bring much convenience to their readers' memories and to the narrative poets' reasonable organization and arrangement of their narrative actions. In effect, those narrative poets have been consciously or unconsciously making a basic 
exploration of and give a profound consideration about the six elementary structures of the following six semiotic atoms of the narrative language of poetic narrative texts including the structure of the semiotic atoms of the phoneme narration, the structure of the semiotic atoms of the allophone narration, the structure of the semiotic atoms of the note (refers to phonetic note) narration, the structure of the semiotic atoms of the tonal narration, the structure of the semiotic atoms of the scale (refers to phonetic scale) narration and the structure of the semiotic atoms of the foot narration (including the metric atoms of the foot narration and the footed atoms of the foot narration in the metric sense) of the narrative language in poetic narrative texts. This exploration of and consideration about the semiotic atoms of phonetic narration in poetic narrative poets meet narrative poets' narrative intention, amuse the readers' metric responses in the course of reading poetic narrative texts, raise their interest in have a good understanding of the musicality, rhythm and the variable diversity of the semiotic atoms of phonetic narration in poetic narrative texts, develop and improve their competence in reading and appreciating those narrative texts, and above all broaden their academic perspectives poetic narrative texts. It can be seen from the analysis mentioned above that the structural variation of the semiotic atoms of the phonetic narration in poetic narrative texts has a potential influence on the change of the narrative structure of poetic narrative texts because the structure of the semiotic atoms of phonetic narration serves as one of the elements that consist of the structural system of the semiotic atoms in poetic narrative texts and one of the structural elements that constitute the modeling system of a relatively stable linear structure used to send, transmit and receive the semantic information of poetic narrative texts.

Of course, the semiotic atoms of the phoneme narration in the narrative language of poetic narrative texts is also a micro-system to record the grammatology of the development and evaluation of poetic language because it is not only a micro-system of phonetic atoms but also that of literal atoms that act as a linear system of sending, transmitting and receiving the textual meanings in the microcosm of poetic narrative texts. Based on the international phonetic system founded in 1888 by Paul Édouard Passy and Daniel Jones while working in International Phonetic Association, phoneme can fall into two categories including vowel phonemes and consonant phonemes in accordance with the vibration of the vocal cords and the height of the sound in the process of pronunciation to the extent the air are prevented. Since the phoneme can produce both sound and meaning, the phoneme of poetic narrative texts can be accepted as the micro-component of the semiotic narrative sub-system of the entire language system of the narrative language in poetic narrative texts. In this case, the vowels in poetic narrative texts ought to be regarded as vowel narrative sign while the consonant the consonant narrative sign. Of course, the micro-system of narrative sign in the system of the narrative language of poetic narrative texts, that is, the proportion and allocation of the narration signs between vowel phonemes and consonant phonemes in the phoneme system of narrative signs have great influence on the semiotic system of syllabic narration in acoustical sense, greater influences on the systematic structure of the metric narration of poetic narrative texts and the greatest influence on both the systematic structure of voice production and meaning transmission of poetic narrative texts. It can be seen from those analyses that the structure of the semiotic system of the phoneme narration plays a very important role in the narrative action of the semiotic system of narrative language in poetic narrative texts. Therefore, a gradual elaboration of the components of the micro-system of the signs of the phoneme narration in the narrative language of poetic narrative texts is of great significance for the enrichment and betterment of the systematic structure of the narrative language in poetic narrative texts. In the sense of the physicist meaning of the semiotic system of the narrative language of poetic narrative texts, there exist the smallest unit in this system, that is, the semiotic atoms of the phoneme narration in poetic narrative texts because each of those atoms has its own stable structure that can make distinction from the structure of other atomic structures.

Apart from the structure of the semiotic atoms of the phoneme narration in poetic narrative texts, the structure of the semiotic atoms of the allophone narration in the same texts is also the very thing that should be paid attention to by the system of the semiotic atoms of the narrative language in poetic narrative texts. Although the phonology that has much to do with phonetics, it was originally proposed in Russia, developed in Europe and spread in America. But beginning with the physicist meaning of the allophone atom of poetic narrative texts, scholars in the field of poetic narratology has neither made a correlativity analysis of the semiotic structure of the allophone narration in poetic narrative texts as much as its nature in terms of the allophone of central vowels, consonants and tones by using the typological index in typology, nor made an exploration of the establishment of the analytical theories directed at the atomic structure of the allophone narration in the narrative language of poetic narrative texts. However, this study is quite necessary in constructing the structural system of the semiotic atoms in poetic narrative texts because the structural combination, distribution and re-organization of the semiotic atoms of the allophone narration in the narrative language of poetic narrative texts will lead to the chrono and spatial transformation in the structures of the narrative language of the poetic narrative texts in 
acoustic sense. This structural transformation will go on to cause the new structural transformation of the structure of the semiotic atoms of allophone narration of the narrative language in poetic narrative texts in the light of reading and writing, which will either directly or indirectly influence or change the atomic structure of the narrative language in poetic narrative texts and then change the structures of narrative chronotope as well as that of narrative sequences in the narrative language of poetic narrative texts. In the end, those changes will either promote or prevent the development of the narrators and the readers of poetic narrative texts in terms of their theoretical cognitive competence on the basis of their own knowledge construction in cognitive phonology for the aim of acquiring the structural changes in their cognitive narration, which will make the readers of poetic narrative texts get a misreading, misunderstanding or even misinterpretation of the semantic structure and the pragmatic structure in reading those texts. Whether this will happen or not counts on whether the judgments of the structural changes of the semiotic atoms of the allophone narration of the narrative language in poetic narrative texts is up to the quantitative changes in the structural changes of the theoretical tools in terms of their topological index, the qualitative changes in this respect or the correlativity analysis of the structure and nature in this aspect. Since the particularity and request of poetic texts in acoustic sense has been entailed, what remains to be done is to give a structural categorization, integration and interpretation of the semiotic atoms of the note narration in the narrative language of poetic narrative texts. Although the earliest acoustic studies appeared in the fields of musical production and studies according to relevant historical records, Anglo-Saxon minstrels like Bede, Cædmon and Cynewulf had already applied into medieval their poetic production of poetic narrative texts some acoustic techniques in the modern sense to build some poetic ties of the semiotic atoms of the note narration with medieval poetry. In the long-term process of poetic production and performance, they made some explorations of the logical laws of the internal structure, the external structure as well as the distribution of the semiotic atoms of note narration in the narrative language of poetic narrative texts by using the semiotic atoms of appropriate length to achieve, record and strengthen the acoustic effects that those poetic narrative texts had produced in their transmission through the air, which on the one hand granted the effective transmission of the semiotic atoms of the narrative language in poetic narrative texts for the transmission rate and exactness of the semantic implications of poetic narrative texts and on the other hand held the attentions of the audience tightly by having a profound knowledge and understanding of the atomic distribution, combination and structural laws of the note narration in the narrative language of the poetic narrative texts that had been sung by the minstrels. At that age of low rate in popularizing printing and writing, the employment and manipulation of the structural laws of the semiotic atoms of note narration in the narrative language of poetic narrative texts could help the minstrels raise, alleviate and control the emotion and spirits of the audience. In that time, this employment and manipulation could be regarded as unexpected strategies for the earlier minstrels to defeat their competitors in the course of their poetic production and performance. Although those minstrels didn't realize the semiotic atoms of note narration in the narrative language of their poetic narrative texts in their production and performance, those atoms in their texts had already helped most of them win the favor of the audience. In the sense of structuralism, those atoms that themselves have their own special structure can act as one of the subsystem of the atomic system of the narrative language in poetic narrative texts. Their structural variation will bring about the same variation in the structural distribution and semantic implications of poetic narrative texts.

In addition to the exploration of the structure of the semiotic atoms of note narration in the narrative language of poetic narrative texts, the studies of the semiotic atoms of phonetic narration in those texts still ought to make a successive study of the structure of the semiotic atoms of tonal narration in the narrative language of poetic narrative texts in the dimension of acoustics. Whether in the performance of poetic narrative texts by medieval minstrels or by modern readers, the oral texts they have sung or performed will all flow in the air at a given frequency from the information sender (the singer or performer of poetic narrative texts) to the information receiver (the audience of those texts). It is obvious that the manipulation of the tonal height of the rising or falling voices the singer use to perform those texts is that of the semiotic atom applied to control the rate frequency and seek for the law of the periodical variation in the narrative language of poetic narrative texts, which in an objective sense needs the singer's or performer's particular familiarity with the adjustment and manipulation of the coding and decoding rules of the structure of the semiotic atoms in the narrative language of poetic texts. Only on the foundation of the familiarity with those rules can the singer or performer of the poetic narrative texts control and employ the frequency of the voice of those texts to limit the pleasant height of its frequency from $1500 \mathrm{~Hz}$ to $3000 \mathrm{~Hz}$ in the course of their performance in order to achieve the effect of pleasing the audience and winning their affirmation, identification and support (Lian-ping \& Gao, 2007, p.56).

With the development of the acousticized studies of the structure of the semiotic atoms of the narrative signs in the narrative language of poetic narrative texts, the studies regarding the semiotic atoms of the scale (refers to phonetic scale) narration in the language of those texts ought to be made of in a swift way to accomplish their 
systematic construction and theoretical framework. The academic evidences in this respect can be found at least in the medieval minstrels' narrative performance, in Auld Lang Syne, the narrative texts of Robert Burns (one of the pre-romanticist poets), and in the theories of Pythagorean school in Greece, the major scholars of this theoretical school include Archytas of Tarentum, Plato and Aristotle because they have laid a solid theoretical foundation for the development of musicological theories (Peng \& Hu, 2009, p.75). That is because the singing or performance of those poetic narrative texts is not only the product of the interaction between linguistic rhythms and tempo rhythms, but also that of melody especially the inter-restriction and interaction between the scale and poetic narrative texts. Therefore, the deeper analysis and study of the abstraction of structural paradigm in terms of the structure of the semiotic atoms of the scale narration in the narrative language of the poetic narrative texts is very important for the exploration of the basic morphological configuration as well as properties and the textual as much as affective implications in the atomic signs of the narrative language in poetic narrative texts. The semiotic atoms of scale narration in the narrative language of those texts consist of the major components of the properties of those texts including their musicality, rhythmicality and structurality due their own stable constituents, arrangements and distributions that has much to do the height of the sounds. In essence, the quantitative relationship from a sound to another can be calculated in accordance with the method that Brook Taylor, a British mathematician proposed in the earlier time of $18^{\text {th }}$ century to describe and calculate the proportion between the vibration frequency of the quadrature and the tension of the quadrature (Li-min \& Huang, 2009, p.156). According to a given mathematical theorem and formula in this regard, it is possible to describe and calculate the structural system of the micro narrative atoms existing in the narrative language of poetic narrative texts. It can be seen from this inference that the studies of the structure of the semiotic atoms of the scale narration in the language of those texts can be switched from previous qualitative analysis to future quantitative analysis for the final aim of giving to this structure a relatively stable mathematical interpretation by means of its quantitative relationship. Just as Pythagoras found the proportion that constitutes the consonance in his musical studies (Yu-feng \& Wang, 2004, p.9), the studies of the structure of the semiotic atoms of the scale narration in the narrative language of poetic narrative texts will be specified in order to justify the existentiality and reasonability of the system of the atomic structure in the future. What can be seen from the knowledge of present stage, the sound and rhythm of the narrative language in poetic narrative texts are merely manifested by the semiotic atoms of foot narration, the semiotic atoms of meter narration and the semiotic atoms of metrical foot narration in the narrative language of poetic narrative texts because those three types of atoms especially the semiotic atoms of foot narration have a given law of atomic structure. It is this very regular structure of those atoms in the semiotic atoms of narrative language in poetic texts that makes the voices of those texts rising and falling in the pace of reasonable rhythm and in the sense of linguistic beauty and metrical musicality by producing sweet consonance in the form of the appropriate proportion between the internal and external components of the semiotic atoms of the foot narration, the semiotic atoms of the rhythmical narration and the semiotic atoms of metrical foot narration while giving the audience of those texts complete and vivid narrative plots, narrative orders, narrative contexts and narrative spaces. Poetic narrative texts are not only read by readers but also recited and sung by them, so the production of poetic narrative texts are bound to meet a higher requirement as far as the structure of the semiotic atoms of their own narrative language. The requirement is that each component of the atomic structure has to follow the basic law of the production or generation of consonance in the acoustic sense and the harmonious structure of the semiotic atoms of the harmonious narrative language of poetic narrative texts can transmit to the audience a succession of elegant rhythms and pleasant consonances. Among the three semiotic atoms of the narrative language in poetic narrative texts, the structure of the atomic atoms of foot narration might be one of the key components of the system of the voice and meaning representation to the system of the semiotic atoms in the narrative language of the poetic narrative texts as a system, for this concept is what poetic critics and readers will pay their first attention to while analyzing and interpreting the narrative language of poetic narrative texts (what poetic critics and readers will pay their second attention to while analyzing and interpreting the narrative language of poetic narrative texts is the semiotic atoms of the rhythmical narration and the semiotic atoms of metrical foot narration of the narrative language of poetic narrative texts). That is because the proportion of the internal structure of the semiotic atoms of the foot narration, the semiotic atoms of the rhythmical narration and the semiotic atoms of metrical foot narration in the narrative language of poetic narrative texts has to follow "the numerical harmony and opposite harmony" (Xin-guo \& Ma, 2002, p.12) in terms of the organization, ordination and distribution of their quantitative relationship. Since everything goes to harmony, the semiotic atoms of foot narration in the narrative language of poetic narrative texts especially those classic ones written in ancient Greek and Latin will bring the singer and audience harmonious symphony in their performance.

Second, the semiotic atoms of the semantic narration in the narrative language of poetic narrative texts are also 
the componential units of semantic narration in a micro sense. Those atoms are the structural units of the semantic narration that are characterized with their multidimensionality, convergence and compositionality.

In the light of the diversity of the structure of the semantic atoms of the narrative language in poetic narrative texts, those atoms are transformed from the textual multi-dimensionality of those texts. In fact, this process of transformation is from the encodement the narrative poets have finished in the construction of their poetic narrative texts with careful organization and plan to the decodement of the semantic structure in the narrative language of poetic narrative texts that the poetic readers and poetic critics have performed after they have had a basic understanding of the encoding process in multidimensional and multi-perspective way. However, what helps readers and critics of poetic narrative texts to make a study or an exploration of the semantic atoms in the narrative language of poetic narrative texts is not only the knowledge and understanding of the narrative poets' competence in the whole process of the narrative poets' encodement in the course of their textual design, plan and construction of poetic narrative texts, but also their deconstructive competence of the textual structure of poetic narrative texts developed after their knowing and understanding of narrative poets' competence mentioned above. As far as the encoding competence of narrative poets is concerned, they need to follow a series of construction rules of poetic narrative poets.

As far as the narrative poets' competences of encodement is concerned, they have to count on a series of rules in terms of textual construction in the process of constructing poetic narrative texts that is firstly to sort out some semiotic atoms of semantic implications out of a large amount of the semiotic signs in the semiotic system of the narrative language of poetic narrative texts to represent the meaning of those texts, secondly follow or change the regular rules of the organization, arrangement and distribution of the linguistic signs in the semiotic system of the semantic signs in poetic narrative texts in order to construct the structural system of the semantic signs of those texts in a systematic order and finally finished the process of encodement of constructing the atomic structure of the semantic signs in those texts. In the light of the poetic readers' or poetic critics' competence of decodement of poetic narrative texts, what they need in course of analyzing and interpreting the poetic narrative texts is to pick out some rules of textual analysis and interpretation in order to dig out the semantic connotation as precise as possible that the internal semiotic system of semantic signs has expressed in the dynamic transformation of the semiotic atoms of semantic signs in poetic narrative texts to disambiguate their textual ambiguity that has been considered to have been unable to or difficult to disambiguate in accordance with their own understanding and judgment of the internal rules of organization, arrangement and distribution of the semiotic atoms of semantic signs of poetic narrative texts by the virtue of the analytical and interpretative rules used to finish those analyses and interpretations of those texts. Therefore, it can be seen that the narrative poets' encodement and the poetic readers' and critics' decodement of poetic narrative texts have to be based on the understanding and judgment of a set of special and precise structural system of semiotic atoms in the semantic signs of the narrative language in those texts. What appears to be similar to this is that both the encodement and decodement can serve poetic readers. The former offers the poetic readers a structural system of semiotic atoms in the semantic signs of the poetic narrative texts that may be regarded to be difficult and complicated in the semiotic structure and implications of the semantic atoms in those texts in order to build a complete semantic system of poetic narrative texts. What makes differences is that the former is the textualization of the thought and awareness that narrative poets have implied in the structural system of the semiotic atoms in the narrative language of poetic narrative texts so as to make it possible that the construction of the semiotic system of the semantic signs in those texts and that of the complete semantic system of poetic narrative texts can be constructed smoothly while the latter is the systematization of the semiotic atoms of semantic signs that have been buried in poetic narrative texts to reflect the narrative thought and modes of narrative poets for the aim of paving way for the understanding, analysis and interpretation of the complicated semiotic system of the semantic signs in poetic narrative texts and that of the complete semantic system of those texts.

In the respect of the convergence of the structure of the semiotic atoms of the semantic signs in the narrative language of poetic narrative texts, this convergence is also reflected in narrative poets' encodement of the systematic construction of the semantic structure of poetic narrative texts and the poetic readers' and the poetic critics' decodement of that that structure in those texts. Whether in the process of encodement or decodement, a lot of importance has been attached to the convergence of the structure of the semiotic atoms of the semantic signs in the poetic narrative texts. The former centers on the semiotic atoms of the semantic signs in the texts mentioned above by putting together the atomic structures that are similar to, identical with and interactive with one another. Although the centralization of those semiotic atoms of semantic signs in poetic narrative texts has only been considered as a tedious convergent movement surrounding those atoms, they permeated into one another, attract one another and influence one another in their actual movement because the narrative poets try to 
"have a control over their own knowledge through standard formula" (Cropley \& Arthur , 2006:391) in order to reduce the generation of the semantic ambiguity in poetic narrative texts. The essay terms the specificity of the movement of the semiotic atoms of poetic narrative texts from one to another as the structural convergence of the semiotic atoms of the semantic signs in those texts. In the process of analyzing and interpretating the construction modes of the semiotic atoms of the semantic signs in poetic narrative texts, the latter makes efforts to clarify which of the semiotic atoms can be considered as the center of all those atoms, in which way they operate and move in order to attract another, influence one another and permeate one another so as to achieve the effects of convergence and makes an analysis of how the narrative poets think of, design and apply the mode of the convergent movement among those semiotic atoms to plan and complete the systematic construction of poetic narrative texts in the process of their construction of the system of the semiotic atoms of the semantic signs in those texts.

In regard to the compositionality of the structure of the semiotic atoms of the semantic signs in poetic narrative texts, the movement and transformation process of those atoms are characterized with a regular compositionality. On the one hand, the movements and changes over a long time has gradually shaped the relatively stable and regular compositional modes of the semiotic atoms of the semantic signs in poetic narrative texts with a remarkable property of internal relationship with one another both in the horizontal and vertical respects at a variable rate from a lower speed to a higher one by demonstrating a linear movement from a higher position to a lower one, from a left direction to a right one, from a partial movement to an entire one and from a horizontal motion to a vertical rise. The structural modes of the compositional movement of the semiotic atoms of semantic signs in poetic narrative texts are consistent with the laws of the movement and changes of matters in philosophical sense, which is to the advantage of the understanding and judgment of the compositional laws that the movement and change of the semiotic atoms of the narrative signs in poetic narrative texts have been following in the process of the encodement of the narrative poets and the decodement of the poetic readers, poetic critics and poetic theorist because it helps them to understand and define the implication of poetic narrative texts. On the other hand, the movements and changes over a long time are also the limitations of the mechanization, modelization and formulation of the movement and change of the semiotic atoms of the semantic signs in poetic narrative texts, which makes it very difficult to promote the pluralization of that movement and change and then result in the semantic homogenization of thise texts. In the physical sense of the readers, this homogeneous linear movement is apt to give readers some tedious stimulus that can not stimulate the central nervous system of their brains to give active aesthetic responses but raise their aesthetic fatigues and trigger their exhaustive aesthetic emotion. Hence, narrative poets and poetic readers, poetic critics and poetic theorists of poetic narrative texts have to take some compensations and moderations in their textual encodement and decodement of those texts to get rid of those negative effects. To sum up, this regular composition of the semiotic atoms of the semantic signs in poetic narrative texts has its own limitations that have to be found and prevented in time.

Third, the semiotic atoms of the pragmatic signs of poetic narrative texts use the micro-pragmatic signs of the narrative language of those texts as the parameters of narrative signs (Kindt et al., 2003, p.93). In terms of the relationship in philosophical sense, the semiotic atoms of the pragmatic signs of poetic narrative texts are the further developments and continuation of the semiotic atoms of the semantic signs of poetic narrative texts including the micro-studies of the semantic implication of poetic narration as well as the narrative contexts of poetic narration of poetic narrative texts instead of the description of grand narrative texts with regards to the abstract narrative system in traditional sense (Bal \& Mieke, 1997, p.4). The narrative meanings of poetic narration in poetic narrative texts can fall into two categories including static narrative meaning and dynamic narrative meaning, each of which has its own stratified structure like the lexical meaning of poetic narration in poetic narrative texts, the syntactical meaning of poetic narration in poetic narrative texts and the discursive meaning of poetic narration in poetic narrative texts. The narrative contexts of poetic narrative texts also have their own compositional and distributional structure including horizontal composition and distribution, vertical composition and distribution as well as the interwoven composition and distribution in both horizontal and vertical dimension. Additionally, as far as the mutual relationship between the narrative meanings and narrative contexts in poetic narrative texts, they are likely to influence each other, depend on each other and compensate each other to shape an appropriate relationship to bear the communication meaning between poets and readers just as what Grice has put in terms of the communication between natural meaning and non-natural meaning (Zhao-xiong \& He, 1999, p.14) to construct a structural system to highlight the value brought by the communication between readers and poets. It can be claimed that the semiotic atoms of the pragmatic signs of poetic narrative texts refer to the structural system of the semantic signs in poetic narrative texts that are capable of enriching, improving and promoting the multi-layered, multimodal and multimedia structure of the semiotic 
atoms of the semantic signs of poetic narrative texts and at the same time regulating the semiotic parameters that can have a control over the informational areas of the communications between narrator and reader (Hühn et al., 2009:59). Each of the semiotic atoms of the pragmatic signs of poetic narrative texts is an instant continuation of the semiotic atoms of the semantic signs in those texts because it has something to do with the synonymity and homogeneity of the semiotic atoms of the semantic signs of poetic narrative texts in both natural and unnatural sense by carrying an aim to give a structural protection to the analysis and interpretation of the semantic implication of poetic narrative texts, to constitute the atomic system of the pragmatic signs of those texts and systematize the studies of the structure of the narrative meanings and narrative contexts as well as that of their mutual relationship in poetic narrative texts in a more profound way.

Fourth, the semiotic atoms of the grammatical signs of poetic narrative texts base their units of narrative constituents on the micro-grammar of those texts. Before dealing with this point, what need to be claimed at first is that the grammar mentioned and discussed here refers to the internal grammatical rules of poetic narration that poetic narrative texts have to follow under the limitation or restraints of the textual grammaticality of those texts in the process of their textual grammatification. In contrast with the studies of grammatification and degrammatification in linguistic grammatics, what the poetic grammatics has been continuing to discuss and explore is to treat the narrative language of poetic narrative texts as the studies and analyses of a semiotic system of grammatical signs with a strong systematicity, theoreticality, logicality, struturality and scientificality according to the grammatical laws and rules of the poetic narrative texts. The linguist who has started the micro-field of linguistic studies is Lucien Tesniere, a French linguist and a pioneer in the studies of the methodology of the micro-field of linguistic studies (En-hui \& Xue, 2006, p.4). The limitation of his studies is that he reduces his studies to the micro-structure of language instead of extending it to that of the narrative language of poetic narrative texts. The semiotic atom of the grammatical signs of the poetic narrative texts discussed in this essay is one of the structural constituents of micro-narration in the structural system of those atoms and the change of their existentiality, compositionality as well as proportion rate of the rules of grammatical structures, compositional frameworks and the stability of the structural models of the narrative grammar of poetic narrative grammar have great impact on system of the semiotic structure and the semantic structure, as much as the generation system of the semiotic structure and semantic structure in the linguistic signs of poetic narrative texts.

Fifth, this essay will give a brief justification to the point that the semiotic atoms of the spatial signs in poetic narrative texts are one of the types of the compositional units of the spatial narration of those texts in a micro way. In regard to the structure of the semiotic atoms of the semantic signs of those texts, the structural system of those atoms is the system that is closely related to the micro-system of the structure of the narrative atoms of geographical spaces, cultural spaces, poetic spaces, imaginary spaces, physicist spaces and the textual spaces of the poetic narrative texts. The micro-system of the semiotic atoms of those texts can shape the macro-system of those texts in accordance with a given rule of compositionality and allocation in a good order because those micro-systems are the indispensable components of the structural system of the spatial narration of poetic narrative system and their structural distribution, composition and reorganization are possible to lead to the partial or total changes of the structural system of the spatial narration of those texts and result in the condensation and extension of the narrative spaces of those texts.

\section{Conclusion}

It can be generally concluded that one the one hand, the theoretical construction of the structural system of the semiotic atoms of the semantic signs of the poetic narrative system can be clarified and justified in the following five respects including the semiotic atoms of the phonetic narration, the semiotic atoms of its semantic narration, the semiotic atoms of its pragmatic narration, the semiotic atoms of its grammatical narration as much as the semiotic atoms of its spatial narration in poetic narrative texts; on the other hand, this study can also promote the research process of the atomicization, mathematicization, musicization (primarily acousticization), physicization as well as spatialization of the semiotic atoms of the semantic signs in poetic narrative system in the future development and improvement of poetic narratology. However, what seems to be pitiful is that due to the limitation of the knowledge accumulation of the author of this study, the studies proposed in this essay need to be deepened in many folds. Therefore, what is highly expected after the temporary completion of this study is the forgiveness of the possible harm that this study might do to some scholars in this field and their suggestions that can be accepted to improve the construction of poetic narratology and correct the unintentional mistakes made in the process of carrying out this studies 


\section{References}

Arthur, C. (2006). In Praise of Convergent Thinking. Creativity Research Journal, 18(3), 391-404. http://dx.doi.org/10.1207/s15326934crj1803_13

Gao, L. (2007). An Overview of Linguistic Theories. Chongqing: (Chongqing Publishing Group) Chongqing Publishing House Press.

He, Z. (1993). A New Introduction to Pragmatics. Shanghai: Shanghai Foreign Language Education Press.

Huang, L. (2009). The Mathematical Background of the Musical Scale and the Temperament Maxim. Journal of Wuhan Conservatory of Music, 10(1), 156.

Ma, X. (2002). A History of Western Literary Theories. Beijing: Higher Education Press.

Narratology, B. M. (1997). Introduction to the Theory of Narrative (2nd ed.). Toronto: University of Toronto Press.

Peng, H. (2009). The Origins of Musical Theories: Pythagorassac Theories, Musical Arts. Journal of Wuhan Conservatory of Music, 10(3), 75.

Peter, H., Wolf, S., \& Jörg, S. (2009). Point of View, Perspective, and Focalization: Modeling Meditation in Narrative. New York: Walter de Gruyter. http://dx.doi.org/10.1515/9783110218916

Tom, K., \& Hans-Harald, M. (2003). What Is Narratology? New York: Walter de Gruyter. http://dx.doi.org/10.1515/9783110202069

Wang, Y. (2004). The Mysterious Harmony of Numbers: On the Pythagorassac Theories of Harmony and Influences. Journal of Jiangsu University of Science and Technology (Social Science Edition), 4(4), 9.

Xue, E. (2006). Meaning $\longleftrightarrow$ Text: A Study of Linguistics, Harbin: Heilong Jiang People's Publishing House Press.

\section{Copyrights}

Copyright for this article is retained by the author(s), with first publication rights granted to the journal.

This is an open-access article distributed under the terms and conditions of the Creative Commons Attribution license (http://creativecommons.org/licenses/by/3.0/). 